\title{
Bursal synovial chondromatosis overlying a solitary osteochondroma of the distal femur: a case report
}

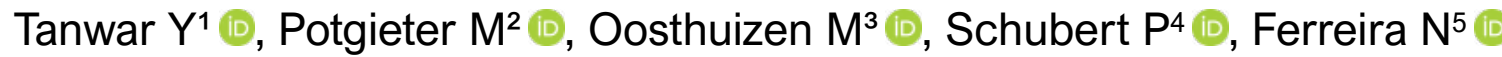

1 MBBS, MS, DNB, MRCS; Stellenbosch University Limb Reconstruction Fellow, Division of Orthopaedic Surgery, Department of Surgical Sciences, Faculty of Medicine and Health Sciences, Stellenbosch University, Cape Town, South Africa

2 MBChB, FC Orth(SA), MMed(Orth); Consultant Orthopaedic Surgeon, Division of Orthopaedic Surgery, Department of Surgical Sciences, Faculty of Medicine and Health Sciences, Stellenbosch University, Cape Town, South Africa

3 MBChB; Registrar, Division of Anatomical Pathology, Tygerberg Hospital, National Health Laboratory Service, Faculty of Medicine and Health Sciences, Stellenbosch University, Cape Town, South Africa

4 MBChB, FCPath(Anat)(SA), MMed(Anat Path), MScMedSc(Cytopathology), MPhil(Paed Path), MIAC; Associate Professor and Consultant Anatomical Pathologist, Division of Anatomical Pathology, Tygerberg Hospital, National Health Laboratory Service, Faculty of Medicine and Health Sciences, Stellenbosch University, Cape Town, South Africa

5 BSc, MBChB, FC Orth(SA), MMed(Orth), PhD; Associate Professor, Consultant Orthopaedic Surgeon and Head of Tumour, Sepsis and Reconstruction Unit, Division of Orthopaedic Surgery, Department of Surgical Sciences, Faculty of Medicine and Health Sciences, Stellenbosch University, Cape Town, South Africa

Corresponding author: Prof. Nando Ferreira, Division of Orthopaedic Surgery, Department of Surgical Sciences, Faculty of Medicine and Health Sciences, Tygerberg Hospital, Stellenbosch University, Cape Town, 7505, South Africa; tel: +27 (21) 938 5456; email: nferreira@sun.ac.za

\begin{abstract}
Synovial chondromatosis and osteochondromas are frequently encountered benign cartilaginous lesions. The concomitant occurrence of these lesions is rare. We report one such case in an 11-year-old female patient and speculate on the common underlying pathogenetic mechanisms which might be involved.
\end{abstract}

Level of evidence: Level 5

Keywords: synovial chondromatosis, secondary synovial chondromatosis, bursal synovial chondromatosis, osteochondroma

Citation: Tanwar Y, Potgieter M, Oosthuizen M, Schubert P, Ferreira N. Bursal synovial chondromatosis overlying a solitary osteochondroma of the distal femur: a case report. SA Orthop J 2020;19(1):46-49. http://dx.doi.org/10.17159/2309-8309/2020/v19n1a7

Editor: Prof. T le Roux, University of Pretoria, Pretoria, South Africa
Received: June 2019
Accepted: September 2019
Published: March 2020

Copyright: ( 2020 Tanwar Y, et al. This is an open-access article distributed under the terms of the Creative Commons Attribution Licence, which permits unrestricted use, distribution and reproduction in any medium, provided the original author and source are credited.

Funding: There are no funding sources to declare.

Conflict of interest: All authors confirm they have no conflicts of interest to declare. 


\section{Introduction}

Osteochondroma, a benign cartilaginous neoplasm, consisting of a cartilage-capped bony projection on the surface of bone, is one the most common benign bone tumours encountered by orthopaedic surgeons. ${ }^{1-3}$ Unlike chondroblastomas, they are not locally aggressive and do not invade the adjacent soft tissues. Since osteochondromas stop growing after physeal fusion, surgical treatment for asymptomatic lesions is rarely warranted. ${ }^{2}$ However, they may cause symptoms secondary to mechanical irritation or compression of adjacent soft tissue structures like tendons, nerves or vessels, in which case excision might be required. Progressive enlargement of an osteochondroma after skeletal maturity or a rapid increase in size at any age, might indicate malignant transformation of the overlying cartilaginous cap and will require surgical resection. ${ }^{4}$

Synovial chondromatosis represents a benign neoplasm presenting as multiple hyaline cartilage nodules in the subsynovial tissue of a joint, tendon sheath or bursa. ${ }^{5}$ Initially, investigators speculated whether osteochondromas and synovial osteochondromatosis represented a true neoplastic condition or merely metaplastic or hamartomatous lesions. ${ }^{1,5}$ Cytogenetic studies, however, have confirmed the true neoplastic nature of both these two conditions (especially multiple osteochondromas) with constant underlying genetic abnormalities. ${ }^{6,7}$ There have been few case reports of concomitant existence of osteochondromas and synovial chondromatosis. ${ }^{8-14}$ We report one such case in an 11-year-old female patient and speculate on the common underlying pathogenetic mechanisms which might be involved.

\section{Case report}

An 11-year-old female patient presented with the history of a firm, painless mass involving the medial aspect of the right distal thigh that had gradually been enlarging over the preceding year. Systemic examination did not reveal any other lesions, showed no distal neurovascular deficit and a normal gait. Local examination confirmed a $10 \times 15 \mathrm{~cm}$ mass on the medial aspect of right distal femur that consisted of a bony component that was adherent to the underlying femur and an overlying soft tissue component. The soft tissue component was cystic and fluctuant with multiple loose bodies palpable within it. Knee range of motion was normal and painless. Laboratory investigations were unremarkable.

Plain radiographs revealed a pedunculated osteochondroma over the medial aspect of right distal femur and multiple wellcircumscribed soft tissue calcifications over the adjacent soft tissue (Figure 1). A magnetic resonance imaging (MRI) scan showed a pedunculated osteochondroma with a cartilage cap measuring $8 \mathrm{~mm}$ in maximum thickness. A large surrounding bursa displacing and attenuating the vastus medialis muscle and containing multiple loose bodies of variable sizes was also noted. A solitary pedunculated osteochondroma with bursal formation and secondary synovial chondromatosis was diagnosed (Figures 2 and 3).

Surgical excision of the lesion was performed through a subvastus approach. The osteochondroma and overlying bursa were resected en masse (Figures 4-6).

Histopathological evaluation showed nodules of variable sizes, with smaller nodules being embedded in hyperplastic subsynovial tissue with granulation tissue and fibrosis (Figure 7). The larger nodules were circumscribed, loose lying, rounded masses of hyaline cartilage with clusters of chondrocytes that demonstrated mild nuclear atypia with nuclear enlargement and occasional binucleation (Figure 8). Pleomorphism, necrosis and mitotic figures were absent. Sections of the femur mass revealed

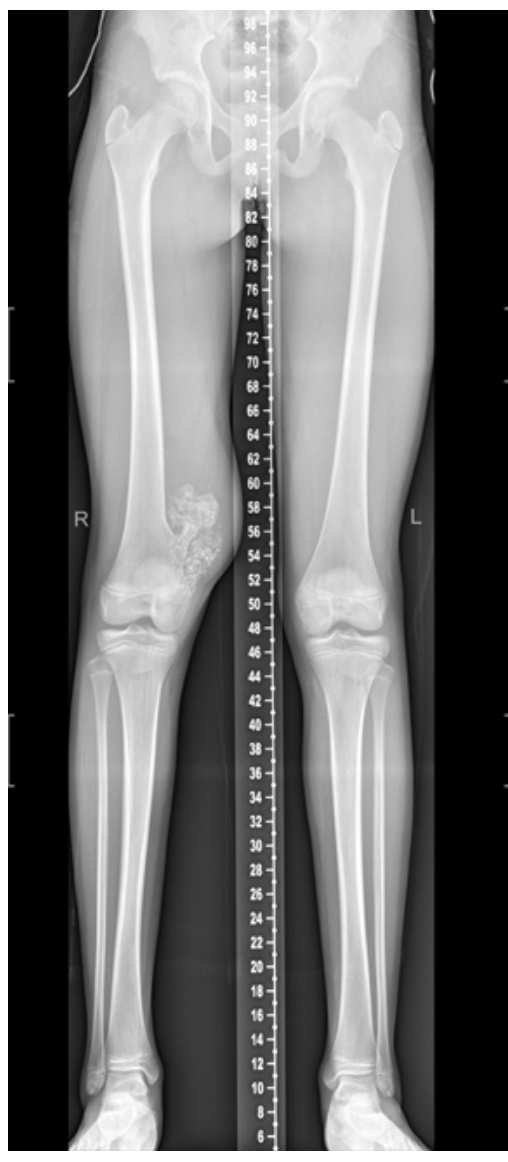

Figure 1. Anteroposterior radiograph showing a pedunculated osteochondroma over the medial aspect of the right distal femur and multiple, well-circumscribed soft tissue calcifications over the adjacent soft tissue
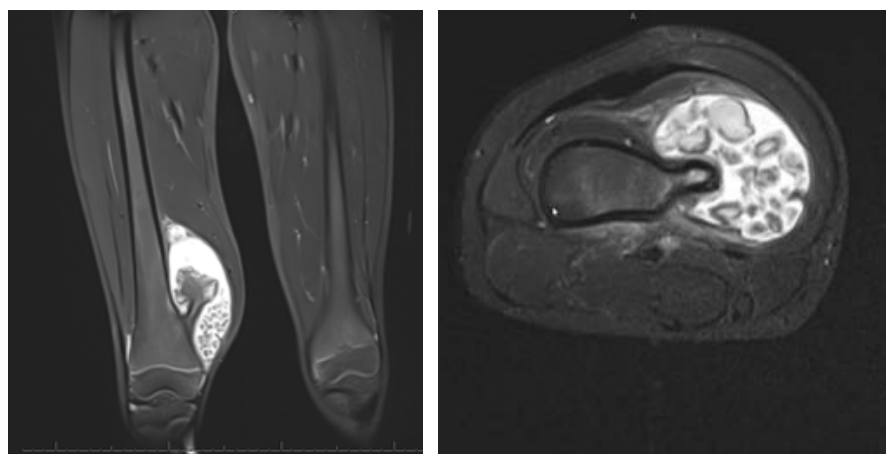

Figures 2 and $\mathbf{3}$. MRI scan coronal and axial views showing an osteochondroma and a large surrounding bursa containing multiple loose bodies

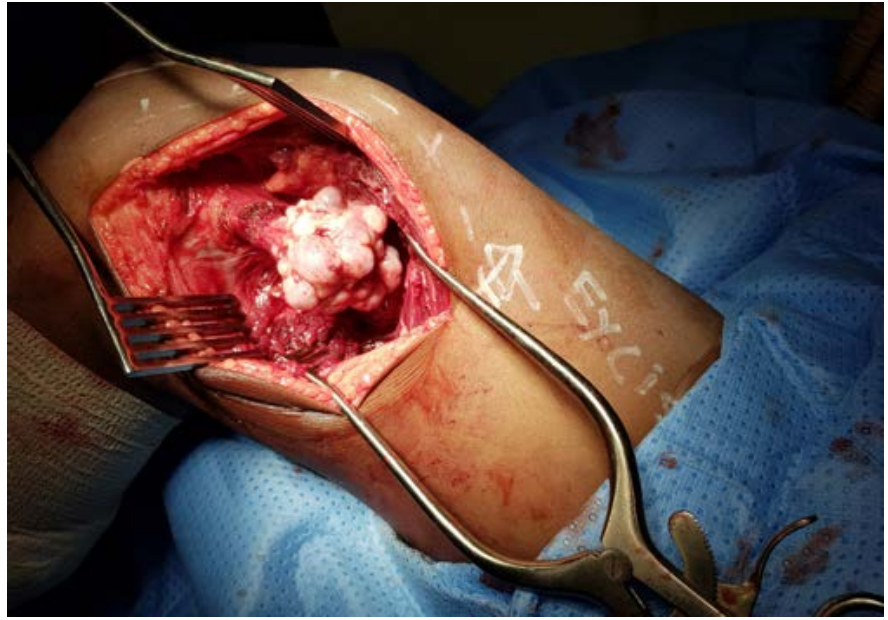

Figure 4. Intra-operative clinical image showing a pedunculated osteochondroma arising from the medial aspect of the distal femur 


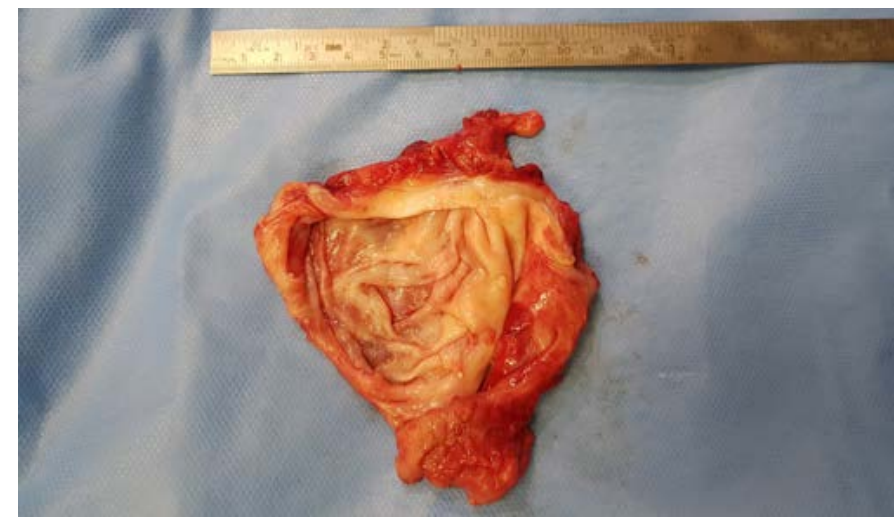

Figure 5. Resected and opened bursa that was overlying the osteochondroma

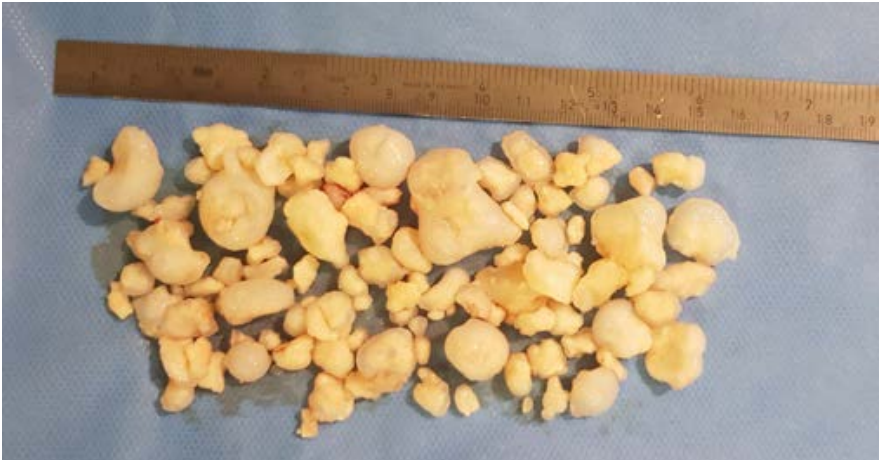

Figure 6. Multiple synovial chondromas found within the bursa

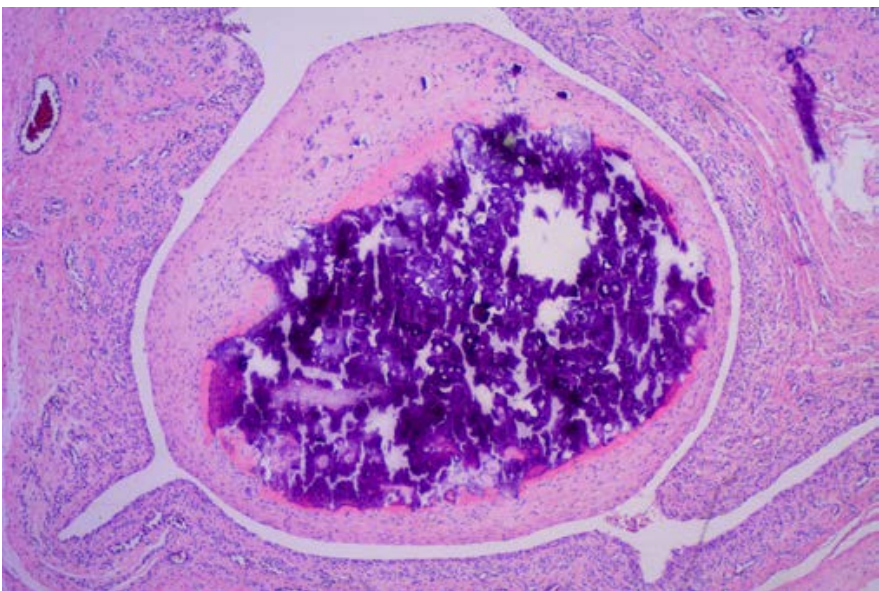

Figure 7. Low magnification view of hypercellular hyaline cartilage nodule embedded in hyperplastic subsynovial tissue with granulation tissue and fibrosis

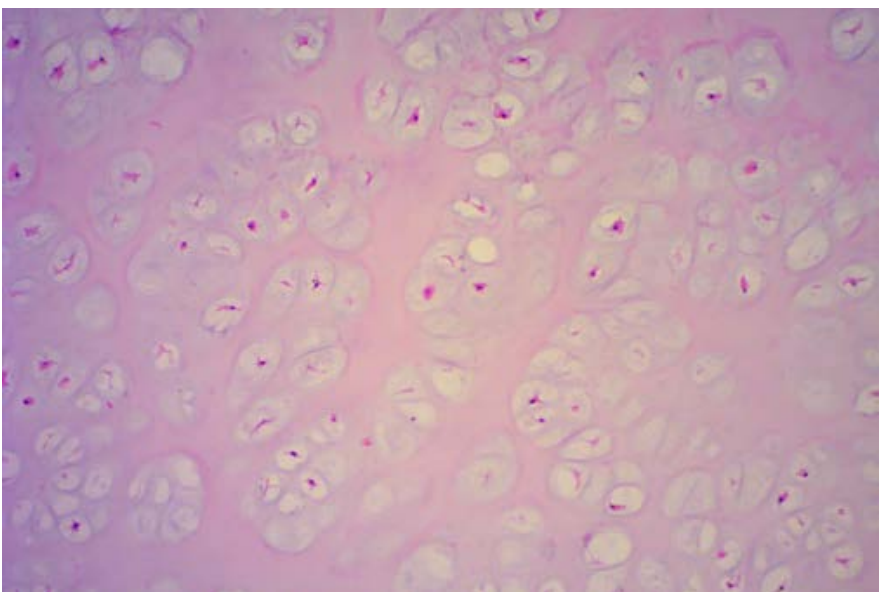

Figure 8. High magnification view of hyaline cartilage with clusters of chondrocytes that demonstrate mild nuclear atypia a benign cartilage tumour comprising a cartilage cap composed of mature hyaline cartilage with overlying fibrous perichondrium. Transition between bone and cartilage cap resembled the growth plate, demonstrating endochondral ossification into mature bone. No features of malignancy were seen. Histological features combined with a review of the radiological images supported the diagnosis of an osteochondroma with associated bursal synovial chondromatosis.

\section{Discussion}

The concomitant existence of two primary neoplastic conditions is a rare occurrence. There are only seven case reports of concurrent synovial chondromatosis and an underlying osteochondroma. ${ }^{8-14}$ Bursa formation over the osteochondroma is secondary to mechanical irritation of the osteochondroma and the overlying tendons. Whether the bursal chondromatosis represents a secondary pathology due to the underlying osteochondroma or a true primary benign neoplastic process, is still unclear. Secondary synovial chondromatosis on the other hand results from mechanical trauma to the hyaline cartilage of a joint, which leads to disassociation of the cartilage cells and secondary seeding over the synovium.

Secondary, intra-articular synovial chondromatosis (loose bodies) is a common condition and is seen in osteochondritis dissecans, neuropathic osteoarthropathy, osteoarthritis, or previous insult of a joint by infection or inflammatory arthritis. Secondary bursal or extra-articular chondromatosis is much less common and is rarely reported. All reported cases have been associated with an underlying osteochondroma. If these lesions were to be truly classified as 'secondary', some mechanical insult to the cartilage cap, leading to disassociation of the cartilage cells and secondary seeding into the bursa would be expected. Dislodgement of lobulated osteochondroma nodules from constant friction is potentially possible, but that does not appear to be the case in this instance.

Histologically, secondary synovial chondromatosis is similar in appearance to the primary but the former is thought not to be clonal and has an identifiable articular primary cause. The histology shows hyperplastic synovium, in which cartilaginous foci form, with the chondrocytes showing mild atypia, binucleation, clustered or diffuse growth in a hyaline cartilage background with areas of calcification. Pleomorphism, necrosis and mitotic figures are absent.

Patients with osteochondromas and synovial chondromatosis have been shown to have underlying genetic abnormalities. Mutations in genes Extostin 1 (EXT-1) and Extostin 2 (EXT-2) are common in patients with osteochondromas. Both sporadic and multiple (hereditary) osteochondromas have been associated with loss of heterozygosity (or somatic loss of function of the wild type allele) of one or more of the EXT loci. ${ }^{7}$ The proteins encoded by EXT-1 and EXT-2 genes help in the formation of heparin sulphate, which in turn binds to Hedgehog protein ligands in the matrix of hyaline cartilage. The Indian Hedgehog signalling pathway inhibits the terminal differentiation of growth plate chondrocytes. Decreased heparin sulphate secondary to mutations in EXT genes leads to abnormal diffusion of Hedgehog ligands, which in turn leads to misdirected growth plate chondrocytes resulting in the formation of osteochondromas. ${ }^{15}$ Dysregulation of the Indian Hedgehog signalling pathway has also been implicated as a causative factor in synovial chondromatosis. ${ }^{6}$ Thus, the underlying mechanism remains common to both the distinct pathologies with the end result being diffusion of chondrocytes into the extra-cellular matrix resulting in either formation of synovial chondromatosis or an osteochondroma. Therefore, concomitant synovial chondromatosis 
and osteochondromas might present more than just what meets the eye, and that is a common underlying pathogenetic mechanism.

Lin et al. described a case of bursal osteochondromatosis which developed several years after osteochondroma excision. ${ }^{16}$ They postulated that it could be due to proliferation of cartilage debris shed from the cartilaginous cap during surgery or biopsy. However, it seems very unlikely to be the case as there was a latent period of several years between the osteochondroma excision and development of bursal chondromatosis. What does seem to be a more plausible explanation is the possible presence of an underlying genetic abnormality, leading to an increased propensity to develop chondral tumours such as synovial chondromatosis and osteochondromas.

The simultaneous occurrence of chondromatosis with osteochondroma also poses a diagnostic dilemma, due to the confusing radiographic imaging that may be mimicking sarcomatous change in an osteochondroma. ${ }^{8}$ Both synovial chondromatosis and chondrosarcoma may show extension into nearby soft tissues and cortical erosion of the bone. An MRI is usually recommended to ascertain the diagnosis, with a clear margin between the underlying cartilage cap and the overlying calcified mass. A permeative pattern and infiltration of the marrow is a strong indicator of malignant transformation.

With regard to the present case, we have presented the concomitant existence of osteochondroma with synovial chondromatosis and speculate on a common underlying genetic abnormality for this co-occurrence. Careful radiographic and histological analysis is necessary to exclude sarcomatous change which the latter might mimic.

\section{Ethics statement}

The authors declare that this submission is in accordance with the principles laid down by the Responsible Research Publication Position Statements as developed at the 2nd World Conference on Research Integrity in Singapore, 2010. All procedures were in accordance with the ethical standards of the responsible committee on human experimentation (institutional and national) and with the Helsinki Declaration of 1975, as revised in 2008.

Ethical approval for this study was obtained from the Stellenbosch University Health Research Ethics Committee (C19/02/006).

\section{Declaration}

The authors declare authorship of this article and that they have followed sound scientific research practice. This research is original and does not transgress plagiarism policies.

\section{Author contributions}

YT: Primary author, drafting of the work, final approval of the version submitted to the journal.

MP: Conception and design of the work, revising it critically for important intellectual content; final approval of the version submitted to the journal.

MO: Review of histopathological specimens, critical revision of work for important intellectual content; final approval of the version submitted to the journal.

PS: Review of histopathological specimens, critical revision of work for important intellectual content; final approval of the version submitted to the journal.

NF: Primary surgeon and corresponding author; conception and design of the work, drafting of the work, revising it critically for important intellectual content; final approval of the version submitted to the journal.

\section{ORCID}

Tanwar Y (D) http://orcid.org/0000-0003-4606-7801

Potgieter M (D) http://orcid.org/0000-0002-9611-4859

Oosthuizen M iD http://orcid.org/0000-0001-6820-9482

Schubert P (iD) http://orcid.org/0000-0003-4422-7349

Ferreira N (iD) http://orcid.org/0000-0002-0567-3373

\section{References}

1. D'Ambrosia R, Ferguson $A B$, Jr. The formation of osteochondroma by epiphyseal cartilage transplantation. Clin Orthop Relat Res. 1968:61:103-15.
2. Mavrogenis AF, Papagelopoulos PJ, Soucacos PN. Skeletal osteochondromas revisited. Orthopedics. 2008;31(10).

3. Giudici MA, Moser RP, Jr., Kransdorf MJ. Cartilaginous bone tumors. Radiol Clin North Am. 1993;31(2):237-59.

4. Tong $\mathrm{K}$, Liu $\mathrm{H}$, Wang $\mathrm{X}$, Zhong $\mathrm{Z}$, Cao $\mathrm{S}$, Zhong $\mathrm{C}$, et al. Osteochondroma: Review of 431 patients from one medical institution in South China. J Bone Oncol. 2017;8:23-9. doi: 10.1016/j.jbo.2017.08.002.

5. Neumann JA, Garrigues GE, Brigman BE, Eward WC. Synovial chondromatosis. JBJS Rev. 2016;4(5). doi: 10.2016/JBJS. RVW.0.00054.

6. Hopyan S, Nadesan P, Yu C, Wunder J, Alman BA. Dysregulation of Hedgehog signalling predisposes to synovial chondromatosis. $J$ Pathol. 2005;206(2):143-50. doi: 10.1002/path.1761.

7. Hameetman L, Bovee JV, Taminiau AH, Kroon HM, Hogendoorn PC. Multiple osteochondromas: clinicopathological and genetic spectrum and suggestions for clinical management. Hered Cancer Clin Pract. 2004;2(4):161-73. doi: 10.1186/1897-4287-2-4-161.

8. Schofield TD, Pitcher JD, Youngberg R. Synovial chondromatosis simulating neoplastic degeneration of osteochondroma: findings on MRI and CT. Skeletal Radiol. 1994;23(2):99-102. doi: 10.1007/ bf00563200.

9. Errani C, Jutte PC, De Paolis M, Bacchini P, Mercuri M. Secondary synovial chondromatosis in a bursa overlying an osteochondroma mimicking a peripheral chondrosarcoma -- a case report. Acta Orthop. 2007;78(5):701-704.

10. Khandwala K, Waheed AA, Alvi MI, Mirza WA, Umer M, Khurshid E. Bursal synovial chondromatosis secondary to underlying osteochondroma in a child. Cureus. 2017;9(12):e1944. doi: 10.7759/cureus.1944.

11. Wang Y, Li L, Chen M, Yang C. Osteochondroma with secondary synovial chondromatosis in the temporomandibular joint. $\mathrm{Br}$ J Oral Maxillofac Surg. 2016;54(4):454-56. doi: 10.1016/j. bjoms.2015.07.014.

12. Peh WC, Shek TW, Davies AM, Wong JW, Chien EP. Osteochondroma and secondary synovial osteochondromatosis. Skeletal Radiol. 1999;28(3):169-74. doi: 10.1007/s002560050495.

13. Gould ES, Baker KS, Huang M, Khan F, Hoda S. Osteochondroma of the hip with adjacent bursal chondromatosis. Skeletal Radiol. 2014;43(12):1743-48. doi: 10.1007/s00256-014-1954-y.

14. Shallop B, Abraham JA. Synovial chondromatosis of pes anserine bursa secondary to osteochondroma. Orthopedics. 2014;37(8):e735-38. doi: 10.3928/01477447-20140728-90.

15. Jones KB, Morcuende JA. Of hedgehogs and hereditary bone tumors: re-examination of the pathogenesis of osteochondromas. lowa Orthop J. 2003;23:87-95.

16. Lin YC, Goldsmith JD, Gebhardt MG, Wu JS. Bursal synovial chondromatosis formation following osteochondroma resection. Skeletal Radiol. 2014;43(7):997-1000. doi: 10.1007/ s00256-014-1821-x. 